\title{
RATE OF EPISIOTOMY AND PERINEAL INJURIES DURING VAGINAL DELIVARIES AT MATERNITY HOSPITAL IN DUHOK CITY
}

\author{
SAMEera SADEEQ FataH ${ }^{*}$ and Iman Yousif ABdulmaleK ${ }^{* *}$ \\ * Dept. of Nursing, Akre Technical Institute/ Duhok Polytechnic University, Kurdistan Region-Iraq. \\ *** Dept. of Obstetrics \& gynecology, Collage of Medicine,University of Duhok, Kurdistan Region-Iraq.
}

(Received: July 22, 2019; Accepted for Publication: August 27, 2019)

\begin{abstract}
Episiotomy is a surgical incision done at the end of the second stage of labor to expand the opening of the vagina to prevent tearing and injury of the perineum during the delivery of the baby. The aim of this study is to estimate the episiotomy and perineal injuries rates and the indication for episiotomy.

A descriptive cross-sectional study was conducted retrospectively between the $1^{\text {st }}$ of Jan. 2018 till 31 of Dec. 2018 at Maternity Hospital in Duhok city. The data were obtained from the information in the case sheets of the women who attended this hospital for vaginal deliveries, the total number of vaginal deliveries was (12302) during that period. The results revealed that the episiotomy and perineal injuries rate was $(23 \%)$, as the episiotomy rate was $(14.7 \%)$ and perineal injuries rate was $(8.3 \%)$ overall. The primiparous episiotomy rate was $(\mathbf{4 0 . 3 \%})$ while multiparous episiotomy rate was $(\mathbf{1 5 . 8 \%})$. The primiparas women were $(52.3 \%)$ of the mothers who had episiotomy and perineal injuries, their episiotomy rate was $(\mathbf{8 8 . 1 \%})$ and the perineal injuries rate was $(11.9 \%)$. While the perineal injuries were more in multiparas mothers $(62 \%)$ and episiotomy rate was $(38 \%)$. The main indication of episiotomy was primigravida, which was done routinely in (71.8\%). The rigid perineum, previous perineal tears, previous episiotomy and previous cesarean section C/S were the indication in $\mathbf{( 1 1 . 8 \% )}$ ) of the mothers. The low and high birth weight were the indications in (7.5\%) in those who needed episiotomy.

Episiotomy and perineal injury (tear) rate was considered as acceptable rate even it is higher than what was reported in developed countries as well as the result revealed that episiotomy was minimizing the rate of perineal injury.
\end{abstract}

KEYWORDS: Episiotomy, Perineal injuries, Vaginal Deliveries, primiparous, multiparous.

\section{INTRODUCTION}

$\mathbf{E}$ pisiotomy is an obstetric intervention which was introduced for the first time in 1714, more than 200 years ago, but it became a common practice from the beginning of 20th century (Ali, Zangana, 2016). It is a surgical incision made into the perineum in the $2^{\text {nd }}$ stage of labour (the second stage of childbirth involves pushing and the delivery of baby) to prevent serious tears and injuries of the perineum (Saadia, 2014).

Episiotomy (EP) required to be performed immediately prior to enlarge the vaginal outlet and to assist the birth of the baby, it can be median, lateral or medio-lateral. This procedure was routinely performed on all primigravida with the idea that a clean surgical incision is better to heal as compared to irregular perineal tears and that routine EP will reduce the incidence of perineal injuries and to protect fetal head and the pelvic floor (Ahmed, 2015).

Internationally, wide variations in EP practice are reported, ranging from routine use in all births to use only when clinically indicated .It is more prevalent in America and Canada than in Europe, because European mothers chose side position during childbirth that provides the gradual stretching of perineum and lower incidence of episiotomy (Carroli et al., 2005).

Restrictive episiotomy is associated with less posterior perineal trauma, less suturing, fewer complications, but is associated with an increased risk of anterior perineal trauma. Currently, there is no scientific evidence is available to support the use of routine episiotomy to prevent intracranial 
hemorrhage in preterm deliveries (Kettle, 2011). A systematic review of randomized controlled trials shows that policies of restrictive EP have benefits compared to routine episiotomy, including less posterior perineal trauma, less suturing and fewer healing complications. However, it being one of the most frequently administered surgical procedures in the world, the efficacy of episiotomy was introduced without strong scientific evidence (Carroli and Mignini, 2009 ).

World Health Organization (WHO) has recommended that EP practice should be limited to strict indications and should not be administered as routine practice (Liljestrand, 2003). The same in the guideline of the American College of Obstetricians and Gynecologists, EP was reported to be restricted (ACOG, 2006). EP is associated with increased blood loss at the time of delivery, hematoma formation, infection, and rarely abscess and recto-vaginal fistula formation (Carroli and Mignini, 2009 ).

Despite these suggestions, prevalence of episiotomy varies significantly between countries. The rate of EP varies between 9.7\% (the lowest) in Sweden, and $100 \%$ (the highest) in Taiwan, in both primipara and multipara women (Kartal et al., 2017)

The suggestion is that EP was to be administered in complicated vaginal deliveries (breech, shoulder dystocia, face presentation, and in forceps and vacuum delivery), incision-related scars in the genital area, poorly healed or $3^{\text {rd }}$ and 4 th degree tears, and fetal distress cases (WHO, 2017).

Also, in a comparison of limited use of episiotomy and routine EP in deliveries without any complication, the WHO reported that episiotomy decreased the risk of posterior perineal trauma and the need for perineal repair, and that there was no difference between the two groups in terms of risks of vaginal and perineal trauma, pain, dyspareunia, and urinary incontinence (Kartal et al., 2017)

The rate of perineal trauma is indicated to be high in countries where EP is frequently administered. Moreover, perineal trauma caused due to EP can affect the sexuality and selfconfidence of women, and lead to perineal pain and infections (Hartmann et al., 2005).There are also studies emphasizing that episiotomy has a protective role against the formation of 3rd degree tears (Lam et al.,2006: Rodriguez et al.,2008).
Perineal injuries mean injury to perineal muscles or anal sphincter and may be to the labia, vagina, urethra, and clitoris. This may occur spontaneously during a vaginal birth, or from the trauma of an operative delivery or by an episiotomy (Bodner-Adler et al., 2018).

Tears, described by Fernando who divided them into four degrees, most frequently involve perineal skin and mucosa (1st degree), they may extend to perineal muscle (2nd degree), anal sphincter complex (3rd degree), and anal mucosa (4th degree) (Lane et al., 2017:Fernando et al., 2015).

In Jordan the PE rate was $41.4 \%$ overall $(91 \%$ of primiparous women and $24 \%$ of multiparous women) (Hussein et al., 2016). The PE rate in a study was done in Sultanate of Oman (66\%) (AlGhammari , 2016). The World Health Organization recommends the restrictive use of episiotomy with a rate of $10-20 \%$ considered acceptable (Hussein et al., 2016).

No study was done for determining the rate of EP and perineal tear in Duhok. The aim of this study which was conducted retrospectively is to determine the rate of episiotomy with its indications and the rate of perineal injuries in the Maternity Hospital in Duhok city.

\section{MATERIALS AND METHODS}

This cross-sectional study was conducted retrospectively at Maternity Hospital in Duhok city, from the $1^{\text {st }}$ of Jan.2018 till 31 of Dec.2018. A tool was prepared for the data collection, the information in the case sheets of the mothers who attended this hospital for vaginal deliveries and had an episiotomy, vaginal tear or both. Prior to data collection, permission to conduct this study was obtained from the Scientific Committee of College of Nursing/ Duhok University and the Ethics Committee of Duhok General Directorate of Health.

The total number of vaginal deliveries was (12305) during that period. The information from archive records included: name, age, phone number, residence, baby weight, parity, past obstetric history, history of previous episiotomy or perineal tears, type of perineal injury, and indication of EP.

This study aimed to find out the rates of EP with its indications that was done during the vaginal deliveries and the perineal injuries which were happened spontaneously. All the data were 
analyzed through the use of Statistical Package for Social Sciences (SPSS) version 23. Categorical measurements are given as number and percentage.

\section{RESULTS}

It was determined that the number of vaginal deliveries was (12305), out of (18995) total deliveries in 2018. The Cesarean section deliveries were $(\mathbf{6 6 9 0})$ ), the rate was $(\mathbf{3 5 \%})$. The number of Primiparous and multiparous were (3685) and
(8620) respectively. Of all the mothers who had vaginal deliveries, the primiparas were $(30 \%)$ and $2842(23.0 \%)$ gave birth with episiotomy (EP), perineal tear (PT) or both. The primiparas episiotomy rate was $(40.3 \%)$ while multiparas EP rate was $(15.8 \%)$. Also, $(97.8 \%)$ of the vaginal deliveries were live births. The highest percentage in age interval from age group (23-30 years) which was $(50.6 \%),(33.8 \%)$ were at age interval (15-22 year). The results revealed that $(89.8 \%)$ of the delivered babies with normal birth weight (2500- 4000gm) as in Table 1.

Table (1): Distribution of the mothers based on demographic and obstetric characteristics

\begin{tabular}{|c|c|c|}
\hline Variables & No. & $\%$ \\
\hline \multicolumn{3}{|l|}{ Delivery methods (no. 18995) } \\
\hline Vaginal deliveries & 12305 & 65 \\
\hline Cesarean section & 6690 & 35 \\
\hline \multicolumn{3}{|l|}{ Obstetric history in vaginal deliveries (no. 12305) } \\
\hline primiparous & 3685 & 30 \\
\hline multiparous & 8620 & 70 \\
\hline \multicolumn{3}{|l|}{ Vaginal deliveries (no. 12305) } \\
\hline Delivery with episiotomy+ perineal tear & 2842 & 23 \\
\hline Delivery without episiotomy & 9463 & 77 \\
\hline \multicolumn{3}{|l|}{ Types of perineal injuries (PI) (no.2842) } \\
\hline Delivery with episiotomy & 1789 & 63 \\
\hline Delivery with perineal tear & 1018 & 35.8 \\
\hline Delivery with episiotomy+ perineal tear & 35 & 1.2 \\
\hline \multicolumn{3}{|l|}{ Parity ( in EP + PT group ) (no.2842) } \\
\hline Primipara ( had one delivery) & 1486 & 52.3 \\
\hline Multipara \& Grandmultipara( had $>2$ or $>5$ delivery) & 1365 & 47.7 \\
\hline \multicolumn{3}{|l|}{ Age interval (year) (no. 2842) } \\
\hline $15-22$ & 961 & 33.8 \\
\hline 23-30 & 1439 & 50.6 \\
\hline $31-38$ & 420 & 14.8 \\
\hline $39-45$ & 22 & 0.8 \\
\hline \multicolumn{3}{|l|}{ Neonatal weight (gm) (no. 2842) } \\
\hline Low birth weight (1000gm- $2400 \mathrm{gm})$ & 155 & 5.5 \\
\hline Normal birth weight (2500gm- $4000 \mathrm{gm})$ & 2551 & 89.8 \\
\hline High birth weight $>4000 \mathrm{gm}$ & 133 & 4.7 \\
\hline
\end{tabular}

The highest percentage $(63.0 \%)$ of mothers had EP only in both primipara and multipara, and the lowest percentage $(1.2 \%)$ in those who had both EP and PT. The primiparas women were $(52.3 \%)$ of the mothers who had EP and PT, their episiotomy rate was $(88.1 \%)$ and the PS rate was $(11.9 \%)$. While the perineal injuries were more in multiparas mothers $(62 \%)$ and EP rate was $(38 \%)$ as shown in Table 2.

Table (2): Distribution of vaginal delivery-related characteristics of the women in terms of parity number

Deliveries related characteristics Parity




\begin{tabular}{clccccc}
\hline & \multicolumn{2}{c}{ Primiparous } & \multicolumn{2}{c}{ Multiparous } & \multicolumn{2}{c}{ Total } \\
\cline { 2 - 7 } & No. & $\%$ & No. & $\%$ & No. & $\%$ \\
\hline Delivery with episiotomy (EP) & 1282 & 86.3 & 507 & 37.4 & 1789 & 63.0 \\
\hline Delivery with perineal tear (PT) & 177 & 11.9 & 841 & 62.0 & 1018 & 35.8 \\
\hline Delivery with EP \& PS & 27 & 1.8 & 8 & 0.6 & 35 & 1.2 \\
\hline Total & 1486 & 52.3 & 1356 & 47.7 & 2842 & 100 \\
\hline
\end{tabular}

In Table 3: About the indications for current episiotomy the most common indication is the primigravida $(71.8 \%)$, then the most common indication is the primigravida $(71.8 \%)$, then age of the mother less than 20 year in $(5.6 \%)$.

Table (3): Indications of episiotomy.

\begin{tabular}{lcc}
\hline Indications & No. & \% \\
\hline *Age of mother below 20 years & 102 & 5.6 \\
\hline $\begin{array}{l}\text { *Bad obstetric history: Breech , Twin, } \\
\text { previous 2 or 3 \& more abortions, } \\
\text { shortning of the second stage of labour. }\end{array}$ & 60 & 3.3 \\
\hline *Previous episiotomy & 72 & 4.0 \\
\hline *Previous vaginal tear & 53 & 2.8 \\
\hline *Previous cesarean section & 56 & 3.1 \\
\hline *Rigid perineum. & 35 & 1.9 \\
\hline *Primipara & $\mathbf{1 3 0 9}$ & $\mathbf{7 1 . 8}$ \\
\hline *Low birth weight (1000g- 2400gm) & 78 & 4.3 \\
\hline High birth weight $>4000 \mathrm{~g}$ & 59 & 3.2 \\
\hline Total & $\mathbf{1 8 2 4}$ & $\mathbf{1 0 0}$ \\
\hline
\end{tabular}

\section{DISCUSSION}

According to the WHO recommendation, the EP should be restricted in uncomplicated cases of delivery. Episiotomy is suggested in order to step up the delivery in cases with fetal distress, in order to prevent intracranial hemorrhage with forceps, vacuum applications, premature or breech delivery, and in cases where exertion of the mother's strength during delivery should be prevented (i.e. cardiac failure), and if there is a risk of 3 rd degree perineum tears especially when 3 rd degree tears occurred in the previous delivery. Babies with occipito-posterior position deliver as face to pubes and increase the risk of perineal injury and instrumental delivery because second stage of labour is prolonged. So it's justified to recommend EP in this case (Kartal, 2017).

In the present study, it was determined that two third of the women $(65.0 \%)$ having vaginal deliveries and the primiparas were (30\%), and the overall rate of EP and PT was (23\%), (40.3\%) of the primipara underwent EP and PT, while $(15.8 \%)$ of the multipara women received EP. This rate is similar to the rate of episiotomy which was $(40.6 \%)$ in primipara women in a study conducted in Italy in 2013 (Kartal, 2017). But is not similar to a study was conducted in Jordan, the EP rate was $(41.4 \%)$ overall (91\% of primiparous women and $24 \%$ of multiparous women) (Hussein et al., 2016).

So there are differences between EP rates depending on the countries. In a study conducted in primipara women in Nigeria, the rate of EP was determined as $(62.1 \%)$. In Australia, they found that the EP rate was (27\%) in Australian-born primipara women, and (48\%) in Vietnamese-born women (Kartal, 2017). In a study conducted in Oman, the rate of EP was 66\% (Al-Ghammari, et al., 2016). 
There is an evidence that EP rate of more than $30 \%$ is not acceptable and episiotomy should be done on selective basis than done as a routine (Ali, Zangana, 2016). A systematic review study on EP which was carried out in Spain, for vaginal birth concluded that restrictive EP policies appear to have a number of benefits than routine EP policies, which associated with reduced anal sphincter laceration rate by $50 \%$, and suggested that the use of EP was not more than $30 \%$ of vaginal deliveries. (Carroli, 2005).

In this study, the PS rate was determined to be higher in multipara women $(62 \%)$, in comparison with $(11.9 \%)$ in primipara. The EP rate in primipara was $(88.1 \%)$ and higher if compared with (38\%) in multipara. These percentages were not gone with Çalışkan et al.,(2003), it was reported that the EP rate was (74.2\%) in Randomized study at tertiary hospitals in Turkey. In another study conducted in Turkey by Karaçam et al.(2013) it was reported that EP was performed in $64 \%$ of vaginal deliveries $(95 \%$ of first deliveries, $48 \%$ of second deliveries, $12 \%$ of third and subsequent deliveries). Another Turkish study, in which the EP was reported to be administered in $92 \%$ of primipara women and $72 \%$ of multipara women ( Hotun-Sahin et al., 2007).

The rate of (10-20\%) considered acceptable by WHO recommendation and has clear guidelines stating that liberal use of EP has failed to reduce the rates of perineal tears (Saadia, 2014). Many countries started to manage this point, France started to reduce the EP rates from $(55.7 \%)$ to (13.3\% ) from 2004 to 2009 without significantly increasing the perineal trauma (Reinbold, 2012). England by setting the policy of avoiding routine episiotomies has managed to reduce the rates to (20\%), EP is not totally free from complications like perineal pain, wound dehiscence and increased bleeding. Routine EP to all women to avoid third and fourth degree perineal tears has been a practice in many developing countries.

Maternal exhaustion is said to occur when the mother fails to push after more than 2 hours of efforts. It has been observed that mothers are asked to push down for a long period of time from early second stage and this leads to maternal exhaustion, this practice also needs re-evaluation and training of the staff. Mothers should not be forced for this action until late in second stage when she has a desire of bearing down, this can also reduce the rates for EP for this indication.
Significant efforts are thus required to reduce the rates of EP especially in primigravida which reported that the routine use of EP avoids perineal injury during delivery. Many reports over the last 20 years verify an increase in the likelihood of perineal trauma. Therefore, the restrictive use of an EP was postulated and is reflected in declining rates of EP over the last 15 years (Saadia, 2014)

Episiotomy administration procedures should be adapted to all healthcare personnel who assist delivery through in-service training and the necessity of avoiding routine administration should be emphasized. In addition, increasing alternative practices such as massage and restricting episiotomy in vaginal deliveries will enable a decrease in the EP rate.

\section{CONCLUSIONS}

Episiotomy and perineal tear rate was considered as acceptable rate even it is higher than what was reported in developed countries, as well as the result revealed that EP was minimizing the rate of perineal injury.

\section{REFERENCES}

Ahmed H. (2015). Post episiotomy care instructions among midwives in Kurdistan region, Iraq.Zanco Journal of Medical Sciences;19(2):1005-10.

Ali HJ \& Zangana JM, (2016). Rate of Perineal Injuries and Episiotomy in a Sample of Women at Maternity Teaching Hospital in Erbil City. Journal of Education and Practice; 7(20): 12-17.

Al-Ghammari K, Al-Riyami Z, Al-Moqbalinb M, AlMarjabi F, Al-Mahrouqi B, Al-Khatri A, et al. (2016). Predictors of routine episiotomy in primigravida women in Oman. Applied Nursing Research; 29131-135.

American College of Obstetricians and Gynecologists. ACOG recommends restricted use of episiotomies; 2006. [cited 2016 May 5]. Available from: http://www.acog.org/AboutACOG/News-Room/News-Releases /2006/ACOG-Recommends\%20Restricted-Useof-Episiotomies.

Bodner-Adler B, Kimberger O, Käfer A, Husslein P \& Bodner K (2018). Management of the perineum during delivery with the Kiwi Omnicup: effects of mediolateral episiotomy on anal sphincter tears in nulliparous women. Gynecologic and obstetric investigation; 83(2): 171-178. 
Çalışkan E, Öztürk N, Akyan B, Dilbaz B, Yalvaç S, Haberal A. Analysis of 47145 deliveries in a tertiary center: an epidemiological view. Gynecology Obstetrics \& Reproductive Medicine. 2003;9:88-91.

Carroli G, Belizan J. Episiotomy for vaginal birth (Cochrane Review). The Cochrane Library, 2005.193(2):1631-4.

Carroli G, Mignini L. Episiotomy for vaginal birth. Cochrane Database Systemic Rev. 2009; (1): CD000081).

Fernando R, Williams A \& Adams, E The management of third and fourth degree perineal tears. Royal College of Obstetricians and Gynaecologists. Green-top Guideline no. 29. June 2015.

Hartmann K, Viswanathan M, Palmieri R, Gartlehner G, Thorp J \& Lohr KN. (2005). Outcomes of routine episiotomy:A systematic review. Journal of the American Medical Associatio Jama; 293(17):2141- 48.

Hotun-Şahin N, Yıldırım G, Aslan E. Evaluating the second stages of deliveries in a maternity hospital, Turkiye Klinikleri. J Gynecol Obst. 2007;17:37-43.

Hussein SAAA, Dahlen HG, Duff M \& Schmied V (2016). The barriers and facilitators to evidencebased episiotomy practice in Jordan. Women and Birth; 29(4): 321-329.

Karaçam Z, Ekmen H, Çalışır H, Şeker S (2013). Prevalence of episiotomy in primiparas, related conditions, and effects of episiotomy on suture materials used, perineal pain, wound healing 3 weeks postpartum, in Turkey: A prospective follow-up study. Iran J Nurs Midwifery Res. ;18:237-45.
Kartal B, Kizılırmak A, Calpbinici P, \& Demir G. ( 2017). Retrospective analysis of episiotomy prevalence. Journal of the Turkish German Gynecological Association;18(4): 190-194.

Kettle C. The pelvic floor. In: Macdonald S, MagillCuerden J, editors. Mayes' midwifery 14th ed. London: Bailliere Tindall; 2011: p. 551-66.

Lam KW, Wong HS, Pun TC. (2006). The practice of episiotomy in public hospitals in Hong Kong. Hong Kong Med J. 2006 Apr;12 (2):94-8.

Lane TL, Chung CP, Yandell PM, Kuehl TJ, Larsen WI. Perineal body length and perineal lacerations during delivery in primigravid patients. Baylor University Medical Center Proceedings, 2017.Taylor \& Francis, 151-3.

Liljestrand J (2008). Episiotomy for vaginal birth: RHL commentary (revised edn). The WHO

Reproductive Health Library. Geneva:World Health Organization.

Rodriguez A, Arenas EA, Osorio AL, Mendez O \& Zuleta JJ (2008). Selective vs routine midline episiotomy for the prevention of third-or fourthdegree lacerations in nulliparous women. American journal of obstetrics and gynecology; 198(3): 285. e1-285. e4.

Saadia Z (2014). Rates and indicators for episiotomy in modern obstetrics-a study from Saudi Arabia. Materia socio-medica; 26(3): 188.

World Health Organization (2017). Reproductive Health. Managing complications in pregnancy and childbirth: a guide for midwives and doctors; 2nd ed. Geneva; ISBN 978-92-4156549-3.

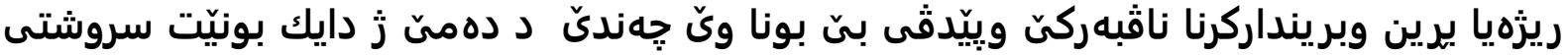

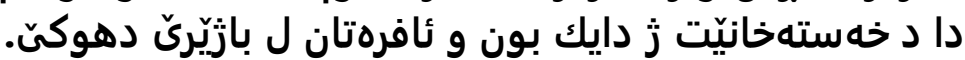

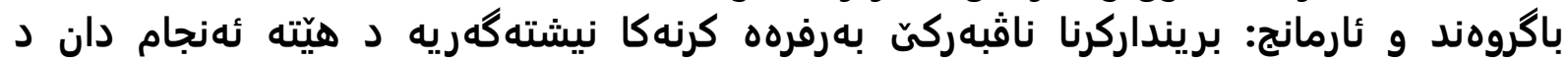

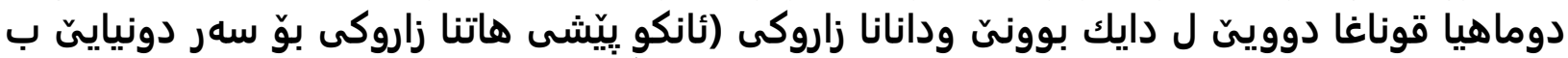

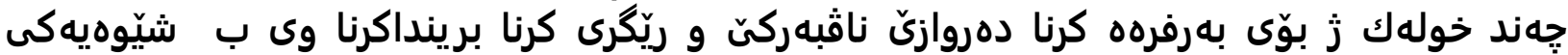

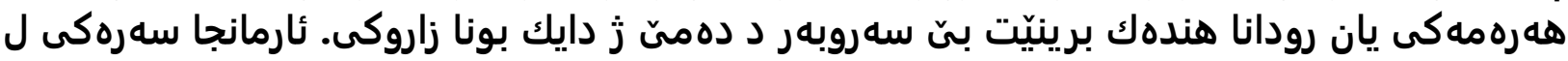

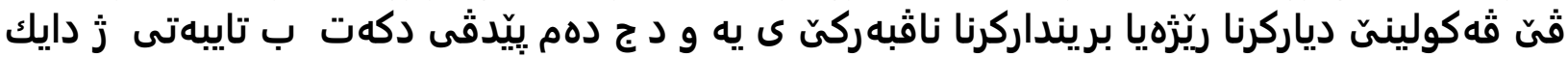

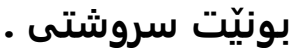

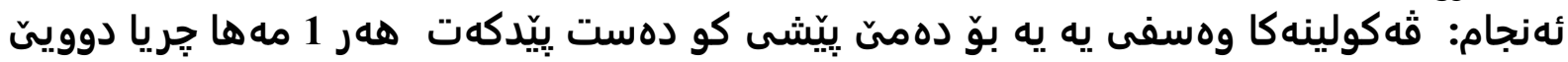

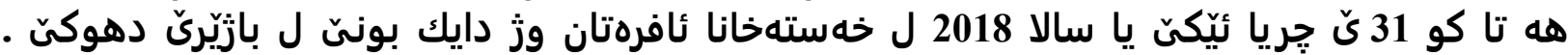

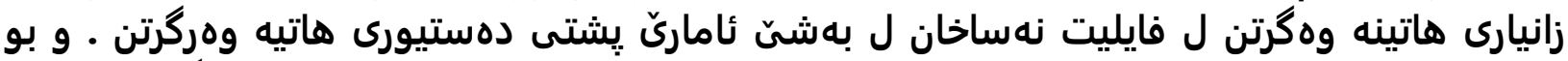

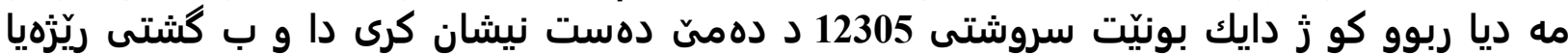




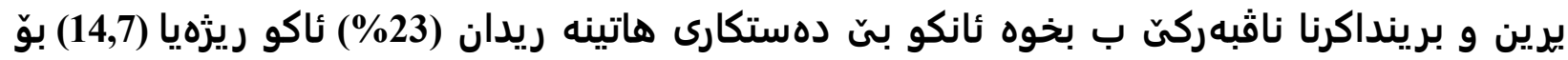

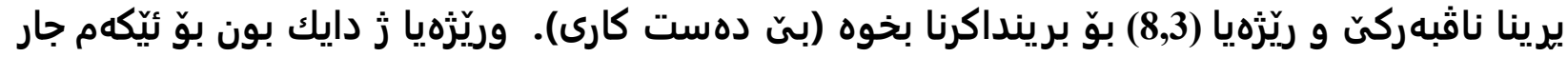

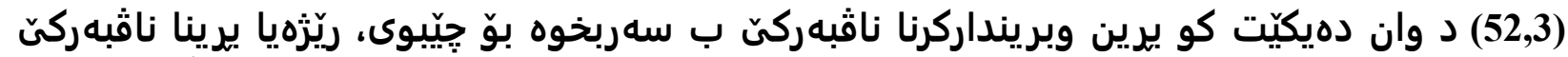

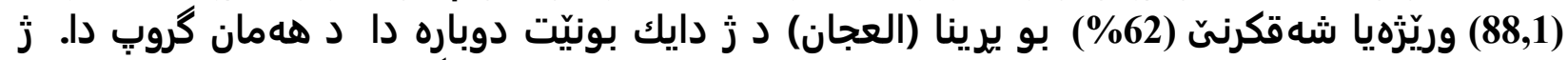

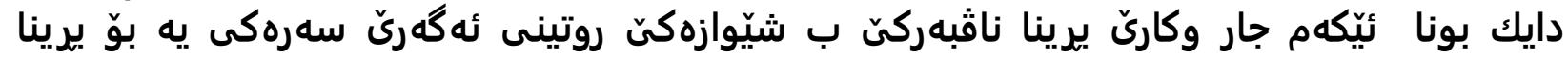

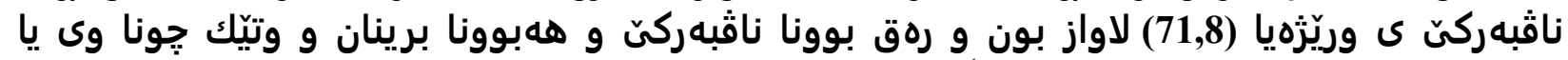

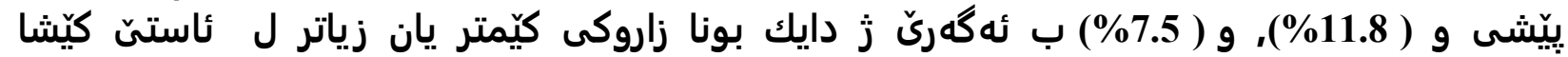
سروشتى.

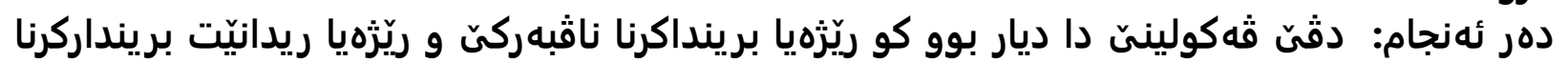

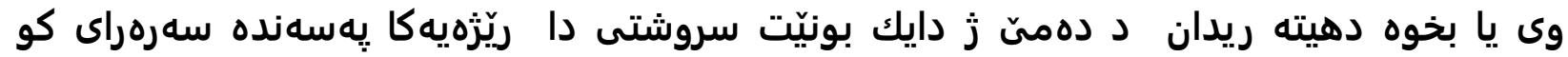

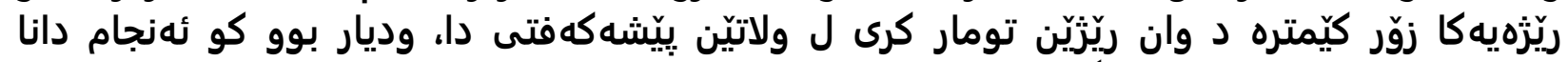

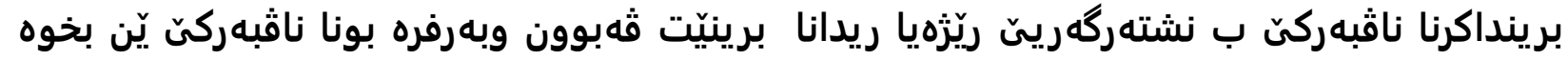

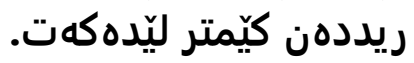

نسبة قص العجان ودواعيه وجرح العجان التلقائي اثناء الولادات المهبلية في مستشفى الولادة والنسائية في مدينة دهوك التلقي

الخلاصة

الخلفية والاهداف: جرح العجان هو شق جراحي يعمل في نهاية المرحلة الثانية من عملية الولادة

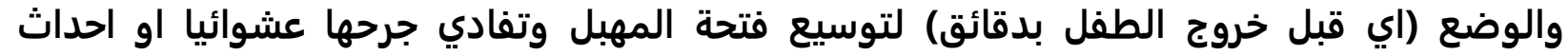

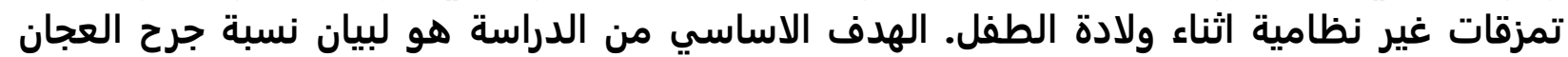
وقص العجان والدواعي لاجرائه خلال الولادة المادية المهبلية.

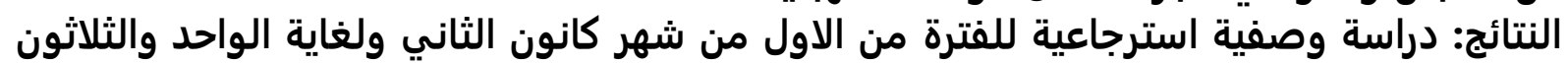

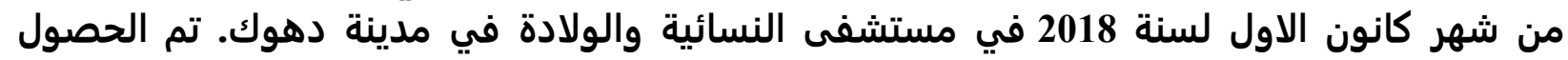

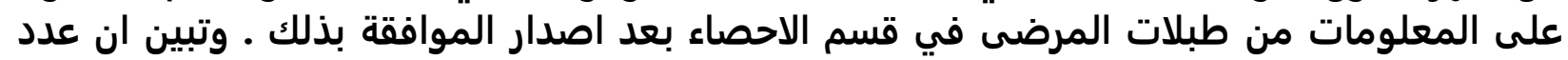

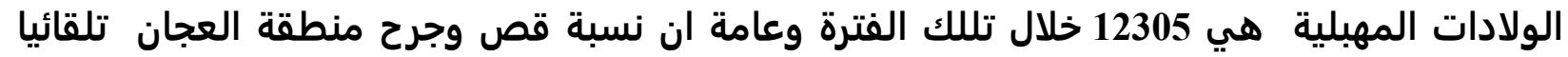

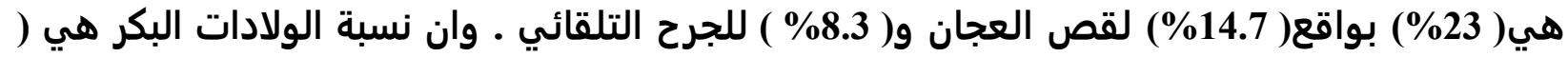

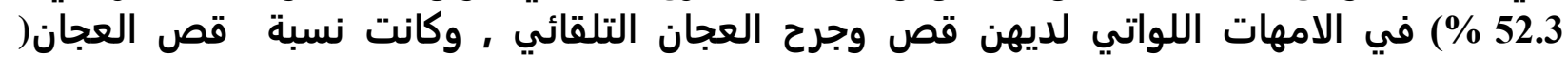

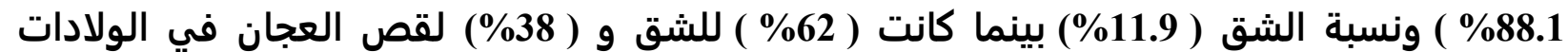

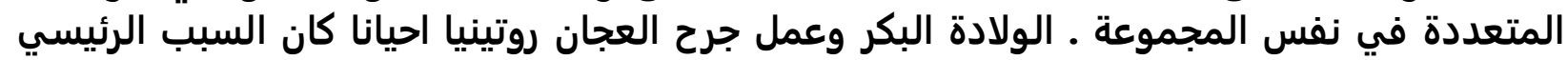

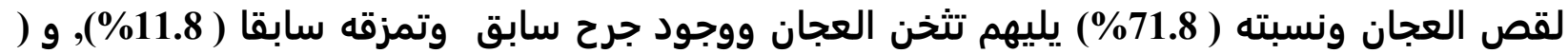

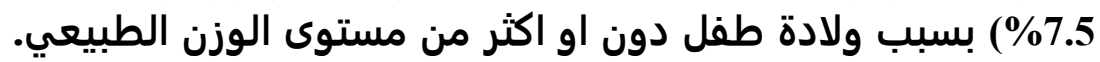

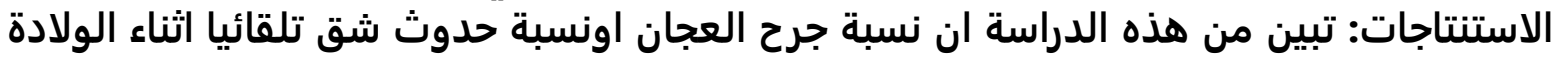

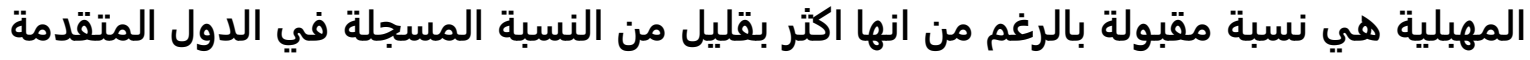
،وتبين ان اجراء جرح العجان يحدد من نسبة حدوث الشبة الشق التلقائي 